\title{
Colistin and Kanamycin Together in Association with Coridothymus capitatus to Enhance their Antimicrobial Activity and Fight Multidrug-Resistance Pathogens
}

\author{
Virginia Fuochi 1,*位, Antonio Rosato ${ }^{2}$, Rosalia Emma ${ }^{1}$, Pio Maria Furneri ${ }^{1(\mathbb{D}}$ \\ 1 Department of Biomedical and Biotechnological Sciences (BIOMETEC), University of Catania, via Santa Sofia 97, \\ Catania 95124, Italy; furneri@unict.it (P.M.F.); \\ 2 Department of Pharmacy - Drug Science, Section of Microbiology, University of Bari, Via Orabona 4, Bari, Italy; \\ antonio.rosato@uniba.it (A.R.); \\ * Correspondence: vfuochi@unict.it;
}

Scopus Author ID 56916150200

Received: 6.07.2020; Revised: 27.07.2020; Accepted: 29.07.2020; Published: 2.08.2020

\begin{abstract}
It should be remembered that bacteria continue to spread and develop new types of resistance, so further actions are needed to deal with antibiotic resistance. As a result, antibacterial drugs have become less effective, resulting in the accelerated discovery of available alternative treatments, including essential oils. The aim of this work was to intensify and promote the action of two antibiotics, kanamycin, and colistin, to fight antibiotic resistance thanks to the action of essential oil obtained from the flowers of Coridothymus capitatus grown on the Iblei mountains. To this end, a comparison of biological and chemical assays was carried out. The results showed a broad antimicrobial power of the essential oil itself and a great synergistic activity in combination with Kanamycin and Colistin against multidrug-resistant bacteria. These combinations increased the range of antibiotics, leading us to speculate that it could be incorporated into new pharmaceutical formulations for therapies of infections caused by increasingly dangerous bacteria. Antibiotic resistance represents an ever-greater danger to human health. This work re-evaluates the use of colistin and kanamycin thanks to the synergistic action found with the addition of a natural substance to pave the way for new therapeutic strategies.
\end{abstract}

Keywords: Thymus essential oil; multidrug resistance bacteria; 3D checkerboard assay; Kanamycin A; Colistin.

(C) 2020 by the authors. This article is an open-access article distributed under the terms and conditions of the Creative Commons Attribution (CC BY) license (https://creativecommons.org/licenses/by/4.0/).

\section{Introduction}

The International Organization for Standardization defines Essential Oils (EOs) as products obtained from raw vegetable material by distillation, mechanical process or dry distillation [1]. Biological properties of EOs have been known since a long time. Indeed, numerous studies in the literature confirm their action (in vitro and in vivo) [2-6]. These activities can be attributed to a large number of molecules such as terpenoids and phenolic compounds, which show antimicrobial activity even when they are tested in the pure form [710] as regard Coridothymus capitatus is a plant belonging to the family Lamiaceae. Common throughout the Mediterranean area, it prefers sandy, sunny, and exposed to salt: Turkey, Tunisia, Greece, Italy, and Spain [11-14]. Nowadays, thymus essential oils are used in clinical as a supplement to conventional medical therapy and in veterinary medicine for dogs, cats, cattle, and sheep (diluted in sweet almond oil) [15]. In addition, TEO has been shown to have antiparasitic [16, 17], insecticidal [18], and antifungal [19] as well as antibacterial activity. 
Moreover, it should be remembered that bacteria continue to spread and develop new types of resistance, so more action is needed to address antibiotic resistance [20]. Even if antibiotics save lives, they can contribute to the development of antibiotic resistance because of their inappropriate use [21, 22]. As a result, antibacterial drugs have become less effective, resulting in an accelerating discovery of available alternative treatments [23], among which bacteriophage therapy [24, 25], combined therapies [26-28], probiotics [29] and essential oils [30-32]. In this regard, most of the essential oils of thyme (Thymus vulgaris) have thymol as the main component [4, 33-36]. Instead, the peculiarity of Coridothymus capitatus is in the very high percentage of CAR [13]. The published studies of $C$. capitatus essential oil indicated anti-inflammatory and antitumor activities as well as antimicrobial activities [37-39].

The aim of this work was to investigate the effectiveness in vitro of the variety of Coridothymus capitatus EO. For this purpose, the interaction of TEO with two drugs was simultaneously assessed by two and three-dimensional checkerboard assays. Growth inhibition curves for each strain, both with the TEO alone and with the combinations, were generated to evaluate the synergistic effect with KAN and/or COL in order to improve the penetration of the antibiotics, enhancing their range of action against multidrug resistant pathogens. Moreover, post-antibiotic effect of the most powerful combination was also investigated.

\section{Materials and Methods}

\subsection{GC-MS analysis.}

Flowers of Coridothymus capitatus (L.) Richb.f were collected during the flowering period in an area named "Lauretum-Rosmarinetum" located in the southwest of the Aleppo pine reserve on Iblei Mountains (Ragusa, Sicily). The TEO was produced and processed (Catania, Sicily) by continuous steam distillation in a 2 meters column without recycling condensation water. The essential oil obtained was dehydrated over $\mathrm{Na}_{2} \mathrm{SO}_{4}$ and filtrated. TEO density values were estimated in a range between $0.930-0.955 \mathrm{~g} / \mathrm{mL}$. CAR solution (purity $\geq 98 \%$.) purchased from Sigma was used as positive internal control, and it had a density of $0.976 \mathrm{~g} / \mathrm{mL}$ at $20^{\circ} \mathrm{C}$. An aliquot was used for gas chromatographer and mass spectrometer measurements, as previously described [40].

In particular, GC-MS analysis was carried out using an Bruker Scion SQ (SCION Instruments, Livingston UK), fitted ZB-5HT Inferno capillary column (30m x 0.25mm, i.d. $0.25 \mu \mathrm{m}$; Zebron ${ }^{\mathrm{TM}}$ Inferno ${ }^{\mathrm{TM}}$, Phenomenex, USA). The injection volume was $1 \mu \mathrm{L}$, and the temperature of the injector was $250^{\circ} \mathrm{C}$. The oven temperature was programmed as follows: it was held at $60^{\circ} \mathrm{C}$ for $3 \mathrm{~min}$, increased to $150^{\circ} \mathrm{C}$ at $3^{\circ} \mathrm{C} / \mathrm{min}$ and then, held at $380^{\circ} \mathrm{C}$ for $3 \mathrm{~min}$. Mass spectra were obtained using the electron impact (EI+) mode at $70 \mathrm{eV}$ with an ion source temperature of $230{ }^{\circ} \mathrm{C}$. Mass spectra were recorded in the $50-1200 \mathrm{~m} / \mathrm{z}$ range. Finally, the structures of molecules were identified by computerized matched in NIST10 spectral library.

\subsection{MIC and MBC assays.}

MDR bacteria were used to evaluate antibacterial activity of essential oil and combinations: both Gram-positive bacteria (Enterococcus faecalis, Staphylococcus aureus) and Gram-negative bacteria (Escherichia coli, Pseudomonas aeruginosa, Klebsiella pneumoniae and Acinetobacter baumannii) (collection of the Laboratory of Applied Microbiology, Department of Biomedical and Biotechnological Sciences, Università degli Studi di Catania). These MDRs, previously isolated from abscess exudates surgically 
eliminated in hospitals, were chosen precisely because they can best represent an example of bacteria that are difficult to eradicate. The strains were designated as MDR by International standard definitions for acquired resistance, as described by Magiorakos et al. [41]. MDR was defined as acquired non-susceptibility to at least one drug in three or more antimicrobial categories. The antibiotics used to assess their level of resistance/sensitivity were summarized in Table S1.

According to the guidelines of CLSI M100 [42], MIC values were determined by the microdilution method. The assay was performed in 96-wells polystyrene plates (Corning® 96 Well Microplates), with CAMHB medium (Cationic Adjusted Muller Hinton Broth; Oxoid). Briefly, a bacterial suspension of $0.5 \mathrm{McF}$ arland was made for each strain under examination and the dilutions in broth were prepared so as to obtain the final concentration of $10^{4}-10^{5}$ $\mathrm{CFU} / \mathrm{mL}$.

Stock solution for TEO was prepared with EtOH to a final range concentrations of $1.0 \%$ $\mathrm{v} / \mathrm{v}-0.001 \% \mathrm{v} / \mathrm{v}$. EtOH maximum concentration was $1.0 \%(\mathrm{v} / \mathrm{v})$, and $\mathrm{MH}$ broth with $1.0 \%$ EtOH was included as growth control. CAR was used as an internal comparative control. Microplates were incubated at $37^{\circ} \mathrm{C}$ overnight, and MIC value $(\mu \mathrm{g} / \mathrm{mL})$ was defined as the lowest concentration, which inhibited the visible growth of the bacterial strains. All determinations were performed six times.

Minimum Bactericidal Concentration (MBC) was performed after that MIC assay has been completed. Briefly, the dilution representing the MIC and two of the more concentrated dilutions were plated on MHA and enumerated to determine viable colonies after incubation at $37^{\circ} \mathrm{C}$ overnight [43]. The $\mathrm{MBC}$ is the lowest concentration that demonstrates a pre-determined reduction (99.9\%) in CFU/mL when compared to the MIC [43].

\subsection{Growth inhibition curves analysis.}

Growth inhibition curves analysis was tested for the pathogens, as previously described [44]. Briefly, a bacterial suspension of $0.5 \mathrm{McFarland}\left(1.5 \times 10^{8} \mathrm{CFU} / \mathrm{mL}\right)$ was prepared after an overnight subculture in Mueller-Hinton broth, and a series of dilutions were prepared to obtain $1.5 \times 10^{5} \mathrm{CFU} / \mathrm{mL}$. The range concentration tested for TEO was $4715-189 \mu \mathrm{g} / \mathrm{mL}$. Inoculated 96-well polystyrene plates were incubated aerobically with shaking at $37^{\circ} \mathrm{C}$ for 24 hours, and OD600 measurements (Model 680 Microplate Reader, Bio-Rad) were made any 30 minutes. All measurements were repeated six different times.

\subsection{Evaluation of double/triple combinations in vitro.}

Each strain was tested with double and triple combination of TEO, KAN, and COL. This evaluation was performed as described by El-Azizi [45]. MIC values of the combination were calculated with respect to the most potent antibiotic, single or in double combination. As previously described [45], to assess the antibiotic combinations therapy in vitro, an interaction code (IC) was created for each combination: for any 2-fold increase or decrease in the MICs values, a numerical value was assigned. Based on this value, the result (interaction type, IT) is defined as Antagonism if IC is -2 or less, Indifferent if $-1<\mathrm{IC}<+1$, Synergism IC $\geq+2$. Triple combination follows same rules but with respect to the most potent double combination. 


\subsection{Two and three-dimensional checkerboard assay.}

Checkerboard assays were performed in order to evaluate synergistic effects between TEO + KAN and TEO + COL [46, 47]. The procedure was performed as followed: TEO was diluted in order to obtain different concentrations, and separately, drugs were diluted in the same way. Briefly, on a microplate, TEO has been diluted by factor 2 starting from column 10 up to 2, and the same in another microplate for the antibiotic KAN or COL, column 1 contained only MH broth. $50 \mu \mathrm{l}$ of the TEO dilutions were transferred from column 10 to column 10 of a new microplate, and each dilution until column 2. From column 10 of antibiotic $50 \mu 1$ were transferred to row A of the microplate, which already contained TEO, and each dilution until row $\mathrm{G}$; nothing was added in row $\mathrm{H}$. A schematic representation is described in Fig. 1A. Range values used for KAN were chosen as defined by CLSI [42]. The interpretation of the results was carried out by calculating the index of fractional inhibitory concentration (FICI) [48].

$$
\mathrm{FICI}=\mathrm{a} / \mathrm{a}^{\prime}+\mathrm{b} / \mathrm{b}^{\prime}=\mathrm{FICa}+\mathrm{FICb}
$$

where $\mathrm{a}=\mathrm{MIC}$ of TEO in the presence of KAN or COL; $\mathrm{a}$ ' $=$ MIC of TEO alone; $b=$ MIC of KAN or COL in the presence of TEO; b' = MIC of KAN or COL alone.

For FIC values lower than 0.5 the combination of antibiotics is defined as synergistic, between 0.5 and 4 is defined as indifferent, and for values $>4$, antagonist.

For the "three-dimensional checkerboard assays," was performed the procedure described by Stein et al. [49]. A schematic representation is described in Fig. 1B. In this case, the FICI for triple antibiotic combination was calculated as follows:

$$
\mathrm{FICI}=\mathrm{a} / \mathrm{a}^{\prime}+\mathrm{b} / \mathrm{b}^{\prime}+\mathrm{c} / \mathrm{c}^{\prime}=\mathrm{FICa}+\mathrm{FICb}+\mathrm{FICc}
$$

where $\mathrm{a}=\mathrm{MIC}$ of TEO in the presence of KAN and COL; ' $\mathrm{a}$ ' $=$ MIC of TEO alone; $\mathrm{b}=\mathrm{MIC}$ of KAN in the presence of TEO and COL; 'b' = MIC of KAN alone; $c=$ MIC of COL in the presence of TEO and KAN; 'c' = MIC of COL alone.

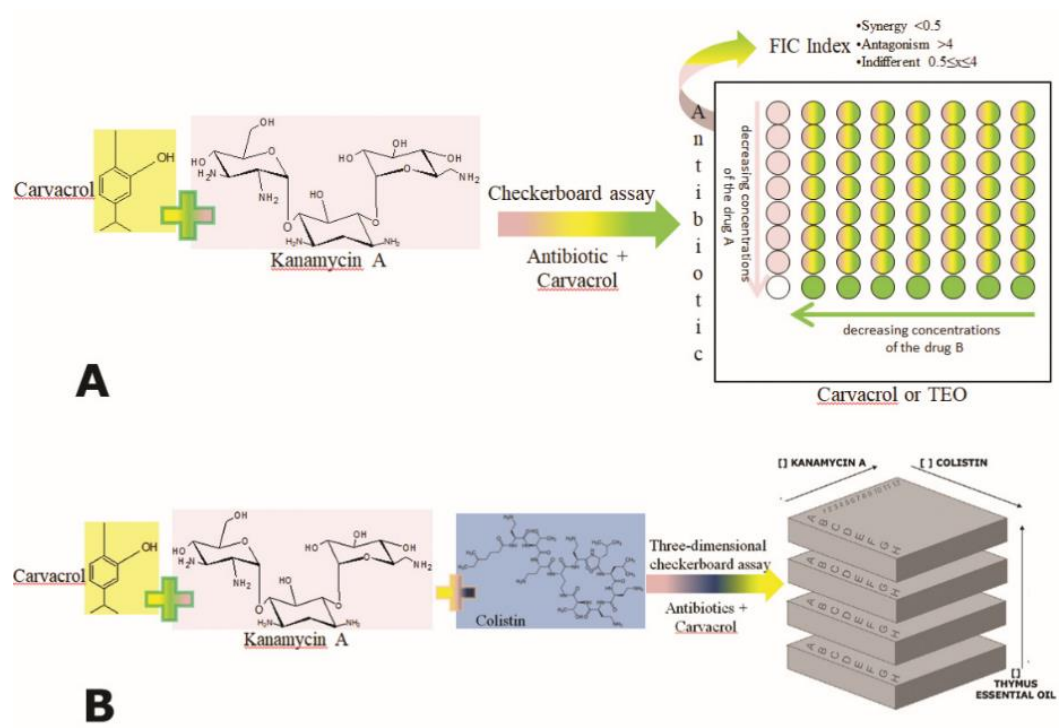

Figure 1. Schematic representation of checkerboard assay to evaluate synergistic effects among two (A) or three (B) different molecules [49]. Adapted from an open access article.

\subsection{Determination of the post antibiotic effect (PAE).}

The determination of PAE was performed as previously described [50, 51]. Briefly, exponentially growing bacteria in $\mathrm{MH}$ broth were adjusted to a concentration of $1.5 \times 10^{5}$ $\mathrm{CFU} / \mathrm{mL}$. Drugs and the combination of drugs were added to culture broth at concentrations 
equal to MIC for the tested strains. After incubation of the samples at $37^{\circ} \mathrm{C}$ for $2.0 \mathrm{~h}$ in a shaking water-bath, drugs were removed by centrifugation $\left(8.500 \mathrm{~g}, 20 \mathrm{~min}, 4^{\circ} \mathrm{C}\right)$ and freedrugs $\mathrm{MH}$ broth was added. Exposed and control cultures were incubated at $37^{\circ} \mathrm{C}$, and the number of CFU/mL was determined at time 0, post-wash, any 2 hours throughout 24 hours. The PAE was determined according to equation $\mathrm{PAE}=\mathrm{T}-\mathrm{C}$ as the difference in time required by test (T) and control (C) cultures for a 1 log increase in colony count [52]. All experiments were performed six times.

\subsection{Statistical analysis.}

Data were summarized using the mean (standard deviation; SD). All results and graphs were generated using GraphPad® Prism ver. 6 software.

\section{Results and Discussion}

\subsection{GC-MS analysis.}

GC-MS analysis of TEO $\left(0.943 \mathrm{~g} / \mathrm{cm}^{3}\right)$ has allowed the identification of 16 compounds representing $97.33 \%$ of the total oil composition. Among these, eight had a percentage greater than $1 \%$. The aromatic fraction (Carvacrol, p-Cymene, $\gamma$-Terpinene) constituted $86.85 \%$ of the oil composition, while the terpenoid fraction appeared to be $10.48 \%$ (Table 1). Chemical analysis performed on TEO obtained from the flowers of Coridothymus capitatus (L.) Richb.f grown in Lauretum-Rosmarinetum located in the southwest of the Aleppo pine reserve on Iblei mountains (Ragusa, Sicily) showed a very peculiar chemotype. In fact, as reported in Table 1, TEO had a great CAR content $(73.04 \%)$ and no thymol in its phenolic fraction. These results have led us to investigate the antibacterial activity of this EO using CAR solution $(\geq 98 \%)$ as an internal comparative control. The complete characterization of Thymus capitatus var. coridothymus essential oil was reported in Table S2. Moreover, Figure S1 showed pertinent chromatogram.

Table 1. Chemical composition of TEO ${ }^{\mathrm{a}}$.

\begin{tabular}{l|l|l} 
Method of extraction & Major components & $\mathbf{b}(\boldsymbol{\%})$ \\
\hline \multirow{5}{*}{ Continuous steam distillation } & p-Cymene & 9.48 \\
\cline { 2 - 3 } & $\boldsymbol{\gamma}$-Terpinene & 4.33 \\
\cline { 2 - 3 } & Carvacrol & 73.04 \\
\cline { 2 - 3 } & Total aromatic fraction & 86.85 \\
\cline { 2 - 3 } & $\beta$-Thujene & 1.16 \\
\cline { 2 - 3 } & $\alpha$-Pinene & 1.20 \\
\cline { 2 - 3 } & $\beta$-Myrcene & 1.37 \\
\cline { 2 - 3 } & Terpinolene & 1.70 \\
\cline { 2 - 3 } & $\beta$-Caryophillene & 5.05 \\
\cline { 2 - 3 } & Terpenoid fraction & 10.48 \\
\cline { 2 - 3 } & Total identified & 97.33
\end{tabular}

${ }^{a}$ Data shown were provided by the manufacture

${ }^{\mathrm{b}}$ percentage greater than $1 \%$ of the total of identified

\subsection{MIC and MBC assays.}

Antibacterial activity of TEO, CAR and KAN is shown in Table 2. As regards MIC values of TEO, they were equal to $754 \mu \mathrm{g} / \mathrm{mL}$ for all strains tested, while MBC values were equal to MIC values except for Pseudomonas aeruginosa where MBC was one dilution lower $(1509 \mu \mathrm{g} / \mathrm{mL})$. MIC values for CAR were equal to $782 \mu \mathrm{g} / \mathrm{mL}$, except for Pseudomonas aeruginosa where a higher MIC value $(3126 \mu \mathrm{g} / \mathrm{mL})$ was reported. For CAR solution, MBC 
values were one dilution lower than MIC values. Therefore, Pseudomonas aeruginosa was the least susceptible of all bacterial strains tested. Despite the difference in CAR content (TEO $73.4 \%$, CAR $\geq 98 \%$ ), the two substances tested had a very similar antibacterial activity when tested alone.

MIC values of KAN and COL complied with those provided by CLSI for Broth Microdilution Method [42]. Moreover, data from literature confirmed limited inhibitory activity of KAN: MIC values against $E$. coli and E. faecalis between $64-1 \mu \mathrm{g} / \mathrm{mL}$ were reported by Fass [53], while $P$. aeruginosa, K. pneumoniae and $A$. baumannii were resistant $[54,55]$.

Table 2. Antimicrobial susceptibility test: MIC and MBC values of TEO, CAR, KAN and COL (expressed as $\mu \mathrm{g} / \mathrm{mL})$.

\begin{tabular}{l|l|l|l|l|l|l}
\multirow{2}{*}{ Strains } & \multicolumn{7}{|l}{ TEO } & CAR & KAN & COL \\
\cline { 2 - 7 } & MIC & MBC & MIC & MBC & MIC & MIC \\
\hline Enterococcus faecalis & 754 & 754 & 782 & 1563 & 64 & 256 \\
\hline Staphylococcus aureus & 754 & 754 & 782 & 1563 & 8 & 256 \\
\hline Escherichia coli & 754 & 754 & 782 & 1563 & 4 & 4 \\
\hline Pseudomonas aeruginosa & 754 & 1509 & 3126 & 1563 & 512 & 32 \\
\hline Klebsiella pneumoniae & 754 & 754 & 782 & 1563 & 512 & 4 \\
\hline Acinetobacter baumannii & 754 & 754 & 782 & 1563 & 512 & 32
\end{tabular}

3.3. Growth inhibition curves analysis.

The growth rates of strains grown with TEO compared to positive control curves were shown in Figure 2: all strains were susceptible up to $754 \mu \mathrm{g} / \mathrm{mL}$, confirming the MIC values obtained by the broth dilution assay. Moreover, a strong reduction was observed at the concentration of 1/2 MIC: A. baumannii and K. pneumoniae showed a reduction of $99.90 \%$ and $99.20 \%$, respectively. The other strains exhibited a reduction of almost $50 \%$ compared to the positive control, except for $S$. aureus, which showed a lower reduction (-30.78\%). The growth rates of strains with combinations of TEO and KAN showed strong synergistic activity against A. baumannii. Indeed, the growth curves of $A$. baumannii with $1024 \mu \mathrm{g} / \mathrm{mL}$ of KAN was comparable to the positive control. The combination KAN $16 \mu \mathrm{g} / \mathrm{mL}$ - TEO $1509 \mu \mathrm{g} / \mathrm{mL}$ caused a partial inhibition of growth $(-52.40 \%)$, while the immediately higher combination (KAN $32 \mu \mathrm{g} / \mathrm{mL}$ - TEO $189 \mu \mathrm{g} / \mathrm{mL}$ ) resulted in complete bacterial inhibition (Fig. 3A).

The combinations CAR+KAN showed no significant synergistic activity. In the same way, the combinations of CAR+COL showed no synergistic activity. Instead, the combination TEO+COL showed great activity, overall on $P$. aeruginosa and $A$. baumannii, with a reduction of growth of $99.80 \%$ and $99.90 \%$ respectively at the following concentration COL $0.50 \mu \mathrm{g} / \mathrm{mL}$ - TEO $189 \mu \mathrm{g} / \mathrm{mL}$ (Fig. 3B).

Finally, the triple combination KAN+COL+TEO caused a total inhibition of growth for E. coli, $P$. aeruginosa and $A$. baumannii at the following concentration: $0.12 \mathrm{COL}-2.0 \mathrm{KAN}$ $-47.12 \mathrm{TEO} \mu \mathrm{g} / \mathrm{mL}$.

\subsection{Two and three-dimensional checkerboard assay.}

Combinations of KAN+TEO, COL+TEO, and control combinations of KAN+CAR and COL+CAR were tested against the same bacteria. FIC Index values were reported in Table 3. Although TEO and CAR solution showed similar antibacterial activity when tested alone, their behavior in combination with the drugs had shown significant differences. The results of the checkerboard assay KAN+TEO and COL+TEO demonstrated how these combinations had a great synergic activity against some pathogenic bacteria. In an outstanding way, FICI of 
KAN+TEO against $A$. baumannii was equal to 0.28 and 0.26 for $S$. aureus, meanwhile, $E$. faecalis showed a FICI slightly higher (0.37). Moreover, FICI values of 0.56, 0.75, and 1.00 were estimated for $K$. pneumoniae, $E$. coli, and $P$. aeruginosa, respectively, showing indifference for this kind of molecules combination.
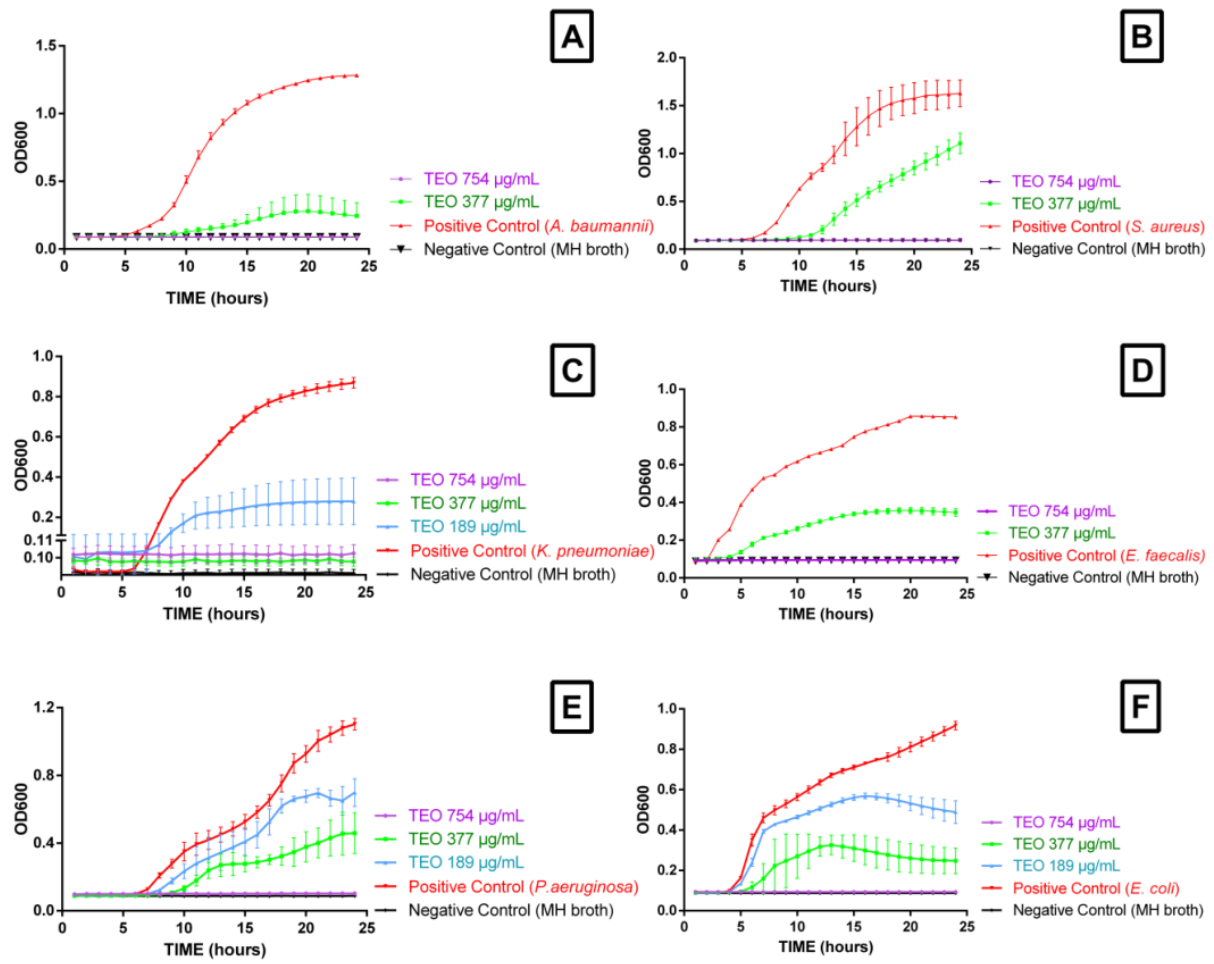

Figure 2. Growth curves inhibition of (A) A. baumannii, (B) S. aureus, (C) K. pneumoniae, (D) E. faecalis, (E) $P$. aeruginos $a$ and (F) E. coli incubated at $37^{\circ} \mathrm{C}$ aerobically overnight with MIC and $1 / 2 \mathrm{MIC}$ values of TEO.

OD600 measurements were done any 30 minutes (Model 680 Microplate Reader, Bio-Rad).
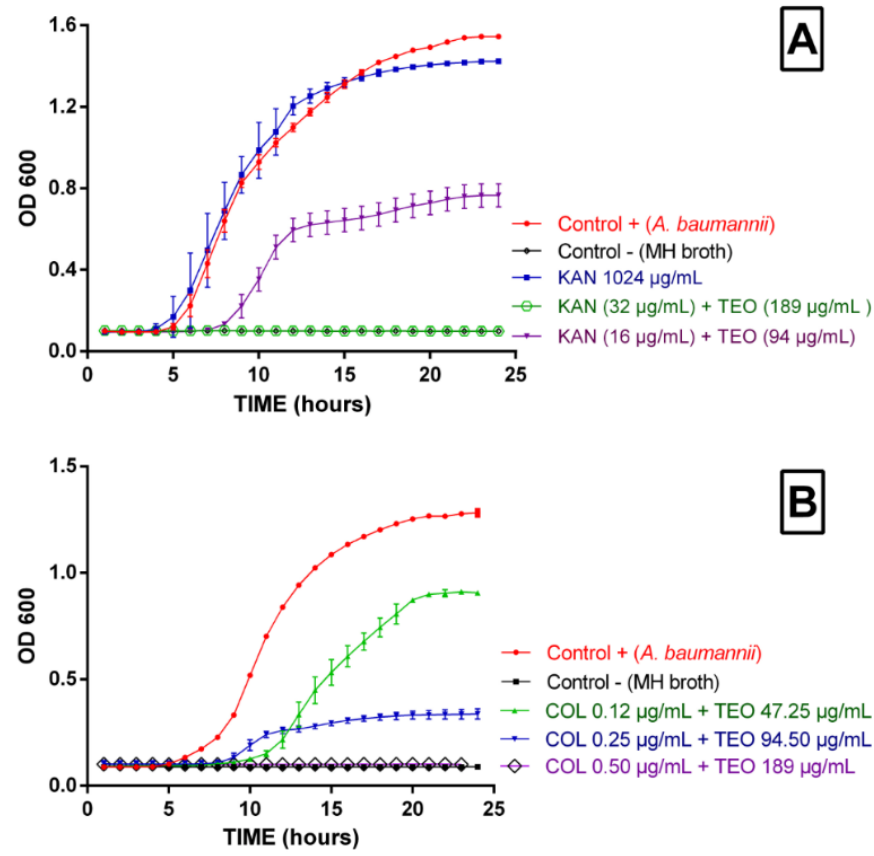

Figure 3. A) Growth curves of Acinetobacter baumannii incubated at $37^{\circ} \mathrm{C}$ with KAN/TEO combinations $32 / 189$ $\mu \mathrm{g} / \mathrm{mL}$ and $16 / 94 \mu \mathrm{g} / \mathrm{mL}$ respectively, for 24 hours. OD600 measurements were done any 30 minutes (Model 680 Microplate Reader, Bio-Rad, Milan, Italy). B) Growth curves of Acinetobacter baumannii incubated at $37^{\circ} \mathrm{C}$ with COL/TEO combinations $0.12 / 47.25 \mu \mathrm{g} / \mathrm{mL}, 0.25 / 94.50 \mu \mathrm{g} / \mathrm{mL}$ and $0.50 / 189 \mu \mathrm{g} / \mathrm{mL}$ for 24 hours. OD600 measurements were done any 30 minutes (Model 680 Microplate Reader, Bio-Rad). 
Instead, FICI of COL+TEO was 0.26 for $P$. aeruginosa and A. baumannii. FICI value of 0.37 was showed for $K$. pneumoniae. For the remaining bacterial strains, the FICI values were greater than 0.5 , showing indifference to the combination of the two molecules. Finally, FICI for the triple combination showed a great synergistic activity with a significant lowering of active concentrations for all strains (0.03-0.38) except for E. faecalis, where the FICI value showed indifference (0.65).

As regard the checkerboard assay of KAN+CAR, results showed FICI values in a range of 0.62-1.03 showing indifference behavior for all bacteria tested. Moreover, indifference behavior was showed for the combination COL+CAR (FICI values range of $0.75-2.00$ ). These differences could be explained by the mechanism of action of phenols contained in TEO. In fact, the doses of TEO below the MIC value could lead to an alteration of bacterial membranes' physical structure with its expansion and destabilization and an increased fluidity, which would increase passive permeability of the bacterial membrane thus enhancing the entrance of the drugs inside the bacterial cell [56].

Table 3. Checkerboard assays of KAN+TEO and COL+TEO combinations, and control combinations $\mathrm{KAN}+\mathrm{CAR}$ and $\mathrm{COL}+\mathrm{CAR}$.

\section{FIC Index}

\begin{tabular}{l|c|c|c|c|c}
\hline Bacterial strains & KAN + TEO & KAN + CAR & COL + TEO & COL + CAR & KAN + COL + TEO \\
\hline E. faecalis & 0.37 & 0.75 & 2.12 & 1.50 & 0.65 \\
\hline S. aureus & 0.26 & 1.03 & 0.53 & 2.00 & 0.38 \\
\hline E. coli & 0.75 & 0.75 & 0.75 & 1.00 & 0.06 \\
\hline P. aeruginosa & 1.00 & 0.63 & 0.26 & 0.75 & 0.03 \\
\hline K. pneumoniae & 0.56 & 0.63 & 0.37 & 1.00 & 0.38 \\
\hline A. baumannii & 0.28 & 0.62 & 0.26 & 1.50 & 0.07
\end{tabular}

3.5. Evaluation of double/triple combinations in vitro.

$\mathrm{KAN}+\mathrm{TEO}, \mathrm{COL}+\mathrm{TEO}$, and $\mathrm{KAN}+\mathrm{COL}+\mathrm{TEO}$ synergisms were also assessed with another kind of assay such as "the double/triple combination in vitro therapy" described by ElAzizi [45]. The results of these combinations were shown in Table 4. When the interaction code (IC) was less than +2 the interaction was classified as indifferent (I). KAN+TEO: ICs for $K$. pneumoniae and $P$. aeruginosa were equal to +1 . Meanwhile it was equal to 0 for $E$. coli.

Table 4. Double and triple combinations assay of TEO with KAN and COL.

\begin{tabular}{|c|c|c|c|c|c|c|c|c|c|}
\hline \multirow{3}{*}{ Bacterial strains } & \multicolumn{5}{|c|}{ Double combinations } & \multicolumn{4}{|c|}{ Triple combination } \\
\hline & \multicolumn{3}{|c|}{ KAN + TEO } & \multicolumn{3}{|c|}{ COL + TEO } & \multicolumn{3}{|c|}{ KAN + COL + TEO } \\
\hline & MIC & IC & IT & MIC & IC & IT & MIC & IC & IT \\
\hline E. faecalis & 16 & +2 & $\mathrm{~S}$ & 32 & +3 & $S$ & 8 & +1 & $\mathrm{I}$ \\
\hline S. aureus & 0.25 & +2 & $\mathrm{~S}$ & 8 & +5 & $\mathrm{~S}$ & 4 & -1 & $\mathrm{I}$ \\
\hline E. coli & 4 & 0 & $\mathrm{I}$ & 1 & +2 & $\mathrm{~S}$ & 0.06 & +4 & $\mathrm{~S}$ \\
\hline P. aeruginosa & 256 & +1 & $\mathrm{I}$ & 0.5 & +6 & $\mathrm{~S}$ & 0.06 & +3 & $S$ \\
\hline K. pneumoniae & 256 & +1 & $\mathrm{I}$ & 0.5 & +3 & $S$ & 0.5 & 0 & $\mathrm{I}$ \\
\hline A. baumannii & 32 & +2 & $\mathrm{~S}$ & 0.5 & +6 & $S$ & 0.12 & +2 & $S$ \\
\hline
\end{tabular}

Moreover, as for the results obtained by checkerboard assay, E. faecalis, S. aureus, and A. baumannii showed ICs equal to +2 , further the combination showed synergism (S) against the strains just mentioned. COL+TEO: this combination showed prodigious results for $P$. aeruginosa and $A$. baumannii with an IC value of +6 , for $S$. aureus with an IC value of +5 and for E. faecalis and $K$. pneumoniae strains with an IC of +3 . Finally, E. coli had an IC value of +2 . Therefore, the double combination COL+TEO showed synergism for all strains tested. 
The triple combination KAN+COL+TEO undergoes the benefits of the two double combinations leading to further synergistic action for some strains: E. coli, P. aeruginosa, and A. baumannii. In contrast, for the strains E. faecalis, S. aureus, and $K$. pneumoniae the combination showed indifference in comparison to the double combinations separately.

\subsection{Determination of the post antibiotic effect (PAE).}

The PAE results were summarized in Table 5, and Figure 4 depicts the PAE of TEO at MIC concentration for all strains studied. In particular, PAE observed for A. baumannii was equal to 5.5 h (Fig.4A), for S. aureus was equal to 8.5 h (Fig. 4B), instead, K. pneumoniae showed a PAE of 9.5 and, P. aeruginosa of 13.5 h (Fig. 4D and F, respectively). E. faecalis showed a PAE of $15.5 \mathrm{~h}$ (Fig. 4C), and finally, it was not possible to detect PAE for E. coli ( $\geq$ $24 \mathrm{~h}$, Fig 4E). Moreover, all strains showed a PAE value of $\geq 24 \mathrm{~h}$ for the triple combination at MIC concentration value.

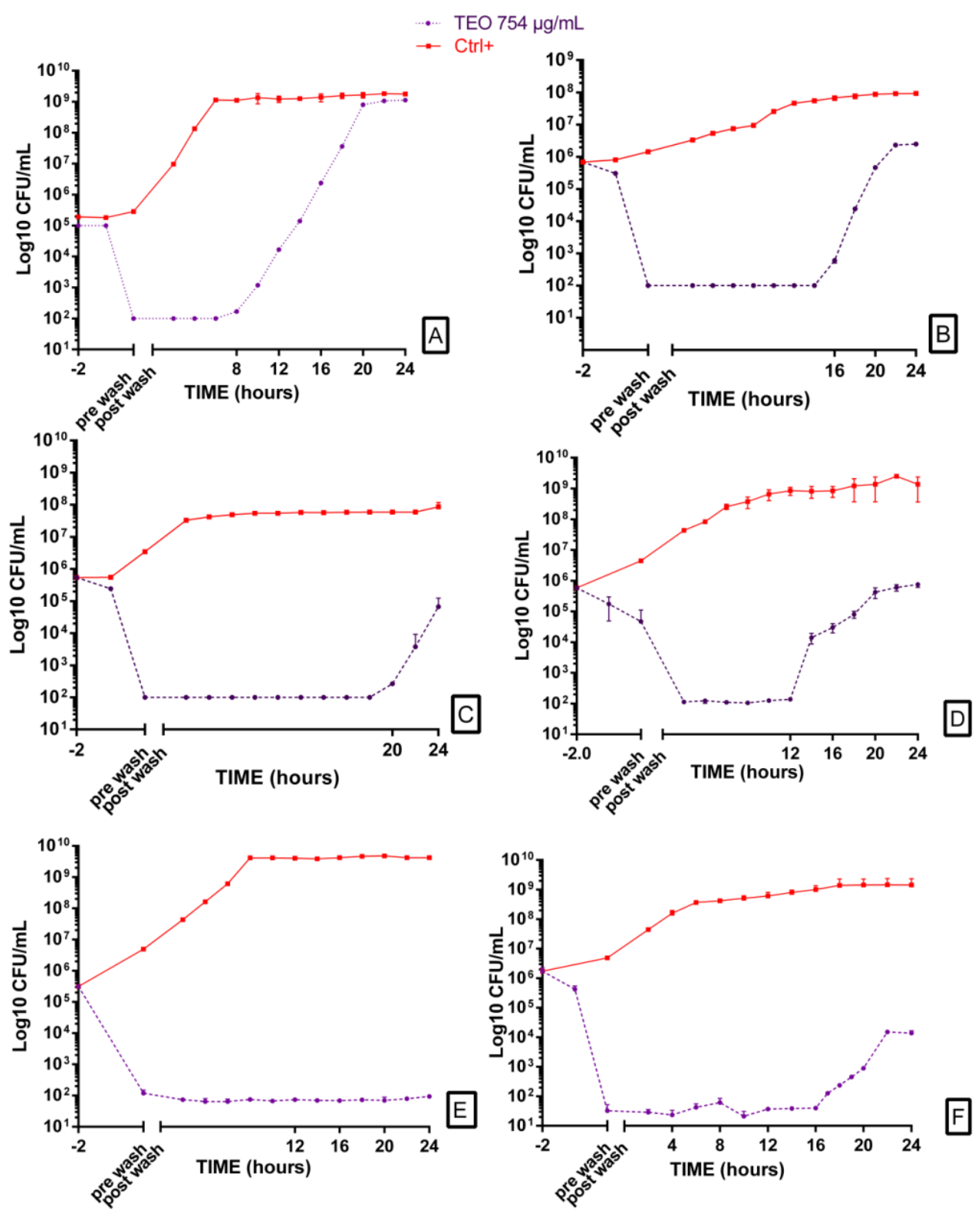

Figure 4. Post antibiotic effect of TEO against Gram-positive and Gram-negative bacteria. TEO at the concentration of MIC and control broth were added to logarithmic phase cultures of (A) A. baumannii, (B) $S$. aureus, (C) E. faecalis, (D) K. pneumoniae, (E) E. coli and (F) P. aeruginosa. 
Table 5. PAE expressed in $\mathrm{h}$ by TEO (MIC, $754 \mu \mathrm{g} / \mathrm{mL}$ ) and a triple combination at the MIC value.

Thymus essential oil

\begin{tabular}{|c|c|c|c|}
\hline Gram positive & PAE & Gram negative & PAE \\
\hline Enterococcus faecalis & 15.5 & Escherichia coli & $>24$ \\
\hline \multirow[t]{3}{*}{ Staphylococcus aureus } & 8.5 & Pseudomonas aeruginosa & 13.5 \\
\hline & & Klebsiella pneumoniae & 9.5 \\
\hline & & Acinetobacter baumannii & 5.5 \\
\hline \multicolumn{4}{|c|}{ Triple combination TEO+KAN+COL } \\
\hline Gram positive & PAE & Gram negative & PAE \\
\hline Enterococcus faecalis & $>24$ & Escherichia coli & $>24$ \\
\hline \multirow[t]{3}{*}{ Staphylococcus aureus } & $>24$ & Pseudomonas aeruginosa & $>24$ \\
\hline & & Klebsiella pneumoniae & $>24$ \\
\hline & & Acinetobacter baumannii & $>24$ \\
\hline
\end{tabular}

Table 6. Comparison between control growth and TEO growth of each strain at $24 \mathrm{~h}(\mathrm{CFU} / \mathrm{mL})$.

\begin{tabular}{l|l|l|l|l} 
& CTRL & TEO $\mathbf{7 5 4} \boldsymbol{\mu g} / \mathbf{m L}$ & $\mathbf{\Delta} \%$ & Adj. $\mathbf{p}$ value \\
\hline E. faecalis & $8.63 \mathrm{e}+07 \pm 3.07 \mathrm{e}+07$ & $6.69 \mathrm{e}+04 \pm 5.73 \mathrm{e}+04$ & -99.92 & 0.0082 \\
\hline S. aureus & $9.26 \mathrm{e}+07 \pm 3.33 \mathrm{e}+06$ & $2.47 \mathrm{e}+06 \pm 2.52 \mathrm{e}+05$ & -97.33 & $1.30 \mathrm{E}-06$ \\
\hline E. coli & $4.23 \mathrm{e}+09 \pm 5.77+07$ & $93.33 \pm 5.51$ & -99.99 & $2.30 \mathrm{E}-08$ \\
\hline P. aeruginosa & $1.43 \mathrm{e}+09 \pm 8.88 \mathrm{e}+08$ & $1.38 \mathrm{e}+04 \pm 2.57 \mathrm{e}+03$ & -99.99 & 0.05 \\
\hline K. pneumoniae & $1.36 \mathrm{e}+09 \pm 9.99 \mathrm{e}+08$ & $7.47 \mathrm{e}+05 \pm 1.37 \mathrm{e}+05$ & -99.94 & 0.078 \\
\hline A. baumannii & $1.78 \mathrm{e}+09 \pm 1.97 \mathrm{e}+08$ & $1.12 \mathrm{e}+09 \pm 1.15 \mathrm{e}+08$ & -37.08 & 0.0075
\end{tabular}

Data are showed as mean $\pm \mathrm{SD}$; $\mathrm{p}$ values were calculated by applying one-way ANOVA with Bonferroni correction for multiple comparisons.

A comparison between control growth and PAE with TEO of each strain at $24 \mathrm{~h}$ was evaluated (Table 6). Significant differences were observed for A. baumannii, S. aureus, E. faecalis, and $E$. coli, which showed reduced growth rates after treatment with TEO compared to control at $24 \mathrm{~h}$. Moreover, substantial inhibition rates were observed for K. pneumoniae and $P$. aeruginosa, but no significant differences were shown.

\section{Conclusions}

Results showed a wide power of TEO and a great synergistic activity by the combination with KAN and COL against multidrug-resistant bacteria. The action was more evident on Gram-negative than on Gram-positive bacteria. The strongest reduction of growth provided by TEO was observed on A. baumannii and $K$. pneumoniae. The combination of TEO + KAN showed high synergistic activity against A. baumannii. In the same way, the combination COL + TEO showed great activity, overall on $P$. aeruginosa and A. baumannii, with an important reduction of growth. Finally, the triple combination KAN+COL+TEO caused a total inhibition of growth for E. coli, P. aeruginosa, and A. baumannii with low doses of all three molecules.

The antimicrobial properties of the complex biological mixture are, in part, ascribed to their lipophilic character, which allows their accumulation into cell membranes causing a break or an interference with biochemical processes necessary for the survival of the microorganism. Our results were consistent with the hypothesis formulated by other authors, according to any EO components that have a critical part to play in antibacterial activity for the synergistic effect $[57,58]$. Therefore, it is possible to conclude that the particular composition of this TEO strongly influences the antimicrobial activity inasmuch as its variability depends on many factors such as environmental conditions, harvest time, the genotype of the plant, and extraction methods as described by some authors [59-61].

Moreover, the synergistic or antagonistic relationship between antimicrobials may result from competition for primary targets. On the other hand, a synergistic multi-target effect may arise, involving ion channels, enzymes substrates, metabolites, receptors, proteins, 
transport proteins groups, DNA/RNA, ribosomes, and other complex chemical and physics mechanisms. Other possible explanations that we take into account may consider the interaction among different biochemical compounds that may cause changes in the structural shape of the molecules resulting in a decreased inhibitory activity. There are several aspects regarding the exact mechanism of the synergistic or antagonistic action between two compounds that could be considered to explain the conclusive effect [62]. These aspects are difficult to clarify without further molecular investigations since, in the current study, the interaction of TEO with two drugs was assessed simultaneously.

Indeed, in order to assess the impact of TEO in association with antimicrobials in our research, we characterized the chemical composition of TEO by GC-MS. Carvacrol was identified as the major component amounting to $73 \%$ of the mixture. This phenolic compound is always present in several species of plant belonging to genus Labiatae, and as reported in scientific literature and important reports, its presence is the primary cause of strong antibacterial action [63]. For our research is possible that antibacterial activity and the synergistic effect may be attributed to the high percentage of this molecule. Several authors demonstrated that phenolic components contained in EOs interact with model membranes and that their antibacterial effect may be ascribed to damage sustained by the microbial lipid fraction. In particular, phenols bind to the amine and hydroxylamine groups of the bacterial membrane, causing an altered permeability and resulting in the death of microorganisms $[2,9,10]$. Furthermore, despite being the main component of this TEO, we must assume that the minor components play a very important role. In fact, the control combinations with pure carvacrol only were not synergistic with respect to the microorganisms tested in the present work.

It is an important highlight as the colistin acts in a similar way of carvacrol. It is a polycation with both hydrophilic and lipophilic domains, and it interacts with the external bacterial membrane, altering its structure mainly through interaction with the lipopolysaccharide. Hence, the combination of EO with polymyxin would help the aminoglycoside drug to enter and act on the 30s subunit of the ribosomes, significantly increasing antibacterial activity. There are many reviews and articles about the synergism among active molecules of EO and antibiotics [64-69], but no one of previous studies evaluated the interaction of TEO with two drugs concurrently and very few studies have exploited the three-dimensional checkerboard assay [70] and a comparison with the more practical method described by El-Azizi [45].

The results shown indicate that although the activity of this TEO is not significantly different compared to the activity shown by other essential oils of thyme, the action of TEO obtained from Coridothymus capitatus in combination with aminoglycoside and polymyxin has significantly reduced the minimum inhibitory concentrations of all three molecules. This reduction also could involve the reduction of possible side effects (high doses of colistin cause nephrotoxicity and neurotoxicity [71], while high doses of kanamycin A can contribute to loss of hearing, also [72]), even if there are controversial thoughts about this argument [73]. Furthermore, natural substances have the disadvantage of having poor water solubility and not having optimal biological stability. These disadvantages can be overcome by the possible incorporation into lipid nanoparticles [74]. Indeed, there are scientific evidence in which "drug delivery vehicles" approach has demonstrated the improvement of efficacy, stability, and bioavailability both of natural compounds and antibiotic drugs [75-77]. 
To sum up, these combinations could be used to increase antibiotics susceptibility, and the active mixture could be incorporated into formulations for the treatment of MDR bacteria. Future investigations will focus on nano safe formulations for the development of new antimicrobial drug delivery systems.

\section{Funding}

This research was funded by Intervento Linea 2 [Grant number 2040101 - UPB 20722142112] (P.I.: Prof. Giovanni Li Volti), Università degli Studi di Catania.

\section{Acknowledgments}

The authors wish to thank Exantiae s.r.l. for providing us the EO of Coridothymus capitatus. Moreover, a special thanks to Dr Fabrizio Medulla for helping with chromatographic analysis, Prof. S. Salomone for the intellectual contribution, and the Scientific Bureau of the University of Catania for the language support.

\section{Conflicts of Interest}

The authors declare no conflict of interest.

\section{Supporting Information}

The supplementary file is available about the designation of MDR bacteria (Table S1). Antimicrobial categories and agents used to define MDR following rules described by Magiorakos [41]: non-susceptible to $\geq 1$ agent in $\geq 3$ antimicrobial categories, and the GC-MS analysis (Table S2). GC characterization of Thymus capitatus var. coridothymus essential oil. Res. Type TIC; Figure S1. Chromatogram of Thymus capitatus var. coridothymus essential oil.)

\section{References}

1. ISO. Geneva, Switzerland, 2013, pp 14.

2. Furneri, P.M.; Fuochi, V.; Lissandrello, E.; G., P.P.; Fresta, M.; Paolino, D. In: Frontiers in Anti-Infective Drug Discovery. Bentham, Ed.; Bentham Science Publishers Ltd, 2017; pp. 23-54, https://doi.org/10.2174/97816810829121170501.

3. Skalicka-Wozniak, K.; Walasek, M.; Aljarba, T.M.; Stapleton, P.; Gibbons, S.; Xiao, J.; Luszczki, J.J. The anticonvulsant and anti-plasmid conjugation potential of Thymus vulgaris chemistry: An in vivo murine and in vitro study. Food Chem Toxicol. 2018, 120, 472-478, https://doi.org/10.1016/j.fct.2018.07.045.

4. Dehghani, N.; Afsharmanesh, M.; Salarmoini, M.; Ebrahimnejad, H. In vitro and in vivo evaluation of thyme (Thymus vulgaris) essential oil as an alternative for antibiotic in quail diet1. J Anim Sci 2019, 97, 2901-2913, https://doi.org/10.1093/jas/skz179.

5. Kubatka, P.; Uramova, S.; Kello, M.; Kajo, K.; Samec, M.; Jasek, K.; Vybohova, D.; Liskova, A.; Mojzis, J.; Adamkov, M.; Zubor, P.; Smejkal, K.; Svajdlenka, E.; Solar, P.; Samuel, S.M.; Zulli, A.; Kassayova, M.; Lasabova, Z.; Kwon, T.K.; Pec, M.; Danko, J.; Busselberg, D. Anticancer Activities of Thymus vulgaris L. in Experimental Breast Carcinoma in vivo and in vitro. Int $J$ Mol Sci, 2019, 20, https://doi.org/10.3390/ijms20071749.

6. El-Boshy, M.E.; Refaat, B.; Qasem, A.H.; Khan, A.; Ghaith, M.; Almasmoum, H.; Mahbub, A.; Almaimani, R.A. The remedial effect of Thymus vulgaris extract against lead toxicity-induced oxidative stress, hepatorenal damage, immunosuppression, and hematological disorders in rats. Environ Sci Pollut Res Int 2019, 26, 22736-22746, https://doi.org/10.1007/s11356-019-05562-8.

7. Cox, S.D.; Mann, C.M.; Markham, J.L.; Bell, H.C.; Gustafson, J.E.; Warmington, J.R.; Wyllie, S.G. The mode of antimicrobial action of the essential oil of Melaleuca alternifolia (tea tree oil). J Appl Microbiol 2000, $88,170-175$. 
8. Lambert, R.J.; Skandamis, P.N.; Coote, P.J.; Nychas, G.J. A study of the minimum inhibitory concentration and mode of action of oregano essential oil, thymol and carvacrol. J Appl Microbiol 2001, 91, 453-462, https://doi.org/10.1046/j.1365-2672.2001.01428.x.

9. Ronsisvalle, S.; Lissandrello, E.; Fuochi, V.; Petronio Petronio, G.; Straquadanio, C.; Crasci, L.; Panico, A.; Milito, M.; Cova, A.M.; Tempera, G.; Furneri, P.M. Antioxidant and antimicrobial properties of Casteanea sativa Miller chestnut honey produced on Mount Etna (Sicily). Nat Prod Res 2017, 33, 1-8, https://doi.org/10.1080/14786419.2017.1413568.

10. Fuochi, V.; Li Volti, G.; Camiolo, G.; Tiralongo, F.; Giallongo, C.; Distefano, A.; Petronio Petronio, G.; Barbagallo, I.; Viola, M.; Furneri, P.M.; Di Rosa, M.; Avola, R.; Tibullo, D. Antimicrobial and AntiProliferative Effects of Skin Mucus Derived from Dasyatis pastinaca (Linnaeus, 1758). Mar Drugs 2017, 15, https://doi.org/10.3390/md15110342.

11. Karousou, R.; Koureas, D.N.; Kokkini, S. Essential oil composition, is related to the natural habitats: Coridothymus capitatus and Satureja thymbra in NATURA 2000 sites of Crete. Phytochemistry 2005, 66, 2668-2673, https://doi.org/10.1016/j.phytochem.2005.09.020.

12. Bounatirou, S.; Smiti, S.; Miguel, M.G.; Faleiro, L.; Rejeb, M.N.; Neffati, M.; Costa, M.M.; Figueiredoe, A.C.; Barroso, J.G.; Pedro, L.G. Chemical composition, antioxidant and antibacterial activities of the essential oils isolated from Tunisian Thymus capitatus Hoff. et Link. Food Chemistry 2007, 105, 146-155, https://doi.org/10.1016/j.foodchem.2007.03.059.

13. Spagnoletti, A.; Guerrinia, A.; Tacchini, M.; Vinciguerra, V.; Leone, C.; Maresca, I.; Simonetti, G.; Sacchetti, G.; Angiolella, L. Chemical Composition and Bio-efficacy of Essential Oils from Italian Aromatic Plants: Mentha suaveolens, Coridothymus capitatus, Origanum hirtum and Rosmarinus officinalis. Nat Prod Commun 2016, 11, 1517-1520.

14. Penalver, P.; Huerta, B.; Borge, C.; Astorga, R.; Romero, R.; Perea, A. Antimicrobial activity of five essential oils against origin strains of the Enterobacteriaceae family. APMIS 2005, 113, 1-6, https://doi.org/10.1111/j.1600-0463.2005.apm1130101.x.

15. I.S.S. Oli essenziali per la salute dell'uomo e la salvaguardia dell'ambiente. Istituto Superiore di Sanità: Roma, 2015; pp. 85.

16. Fabbri, J.; Maggiore, M.A.; Pensel, P.E.; Denegri, G.M.; Gende, L.B.; Elissondo, M.C. In vitro and in vivo efficacy of carvacrol against Echinococcus granulosus. Acta Trop 2016, 164, 272-279, https://doi.org/10.1016/j.actatropica.2016.09.001.

17. Saha, S.; Lachance, S. Effect of essential oils on cattle gastrointestinal nematodes assessed by egg hatch, larval migration and mortality testing. J Helminthol 2019, 94, https://doi.org/10.1017/S0022149X19001081.

18. Kasrati, A.; Alaoui Jamali, C.; Bekkouche, K.; Wohlmuth, H.; Leach, D.; Abbad, A. Comparative evaluation of antioxidant and insecticidal properties of essential oils from five Moroccan aromatic herbs. J Food Sci Technol 2015, 52, 2312-2319, https://doi.org/10.1007/s13197-014-1284-z.

19. Mugnaini, L.; Nardoni, S.; Pinto, L.; Pistelli, L.; Leonardi, M.; Pisseri, F.; Mancianti, F. In vitro and in vivo antifungal activity of some essential oils against feline isolates of Microsporum canis. J Mycol Med 2012, 22, 179-184, https://doi.org/10.1016/j.mycmed.2012.04.003.

20. C.D.C. Antibiotic Resistance Threats in the United States, 2019. Centers for Disease Control and Prevention: Atlanta, GA: U.S., 2019.

21. Michael, C.A.; Dominey-Howes, D.; Labbate, M. The antimicrobial resistance crisis: causes, consequences, and management. Front Public Health 2014, 2, https://doi.org/10.3389/fpubh.2014.00145.

22. Canton, R.; Horcajada, J.P.; Oliver, A.; Garbajosa, P.R.; Vila, J. Inappropriate use of antibiotics in hospitals: the complex relationship between antibiotic use and antimicrobial resistance. Enferm Infecc Microbiol Clin 2013, 31, 3-11, https://doi.org/10.1016/S0213-005X(13)70126-5.

23. W.H.O. Antimicrobial resistance: global report on surveillance. World Health Organization: Geneva, Switzerland, 2014.

24. Weber-Dabrowska, B.; Zimecki, M.; Kruzel, M.; Kochanowska, I.; Lusiak-Szelachowska, M. Alternative therapies in antibiotic-resistant infection. Adv Med Sci 2006, 51, 242-244.

25. Ujmajuridze, A.; Chanishvili, N.; Goderdzishvili, M.; Leitner, L.; Mehnert, U.; Chkhotua, A.; Kessler, T.M.; Sybesma, W. Adapted Bacteriophages for Treating Urinary Tract Infections. Front Microbiol 2018, 9, https://doi.org/10.3389/fmicb.2018.01832.

26. Tran, T.B.; Wang, J.; Doi, Y.; Velkov, T.; Bergen, P.J.; Li, J. Novel Polymyxin Combination With Antineoplastic Mitotane Improved the Bacterial Killing Against Polymyxin-Resistant Multidrug-Resistant Gram-Negative Pathogens. Front Microbiol 2018, 9, https://doi.org/10.3389/fmicb.2018.00721.

27. Broussou, D.C.; Lacroix, M.Z.; Toutain, P.L.; Woehrle, F.; El Garch, F.; Bousquet-Melou, A.; Ferran, A.A. Differential Activity of the Combination of Vancomycin and Amikacin on Planktonic vs. Biofilm-Growing Staphylococcus aureus Bacteria in a Hollow Fiber Infection Model. Front Microbiol 2018, 9, https://doi.org/10.3389/fmicb.2018.00572.

28. Worthington, R.J.; Melander, C. Combination approaches to combat multidrug-resistant bacteria. Trends Biotechnol 2013, 31, 177-184, https://doi.org/10.1016/j.tibtech.2012.12.006. 
29. Wang, J.; Ji, H.; Wang, S.; Liu, H.; Zhang, W.; Zhang, D.; Wang, Y. Probiotic Lactobacillus plantarum Promotes Intestinal Barrier Function by Strengthening the Epithelium and Modulating Gut Microbiota. Front Microbiol 2018, 9, https://doi.org/10.3389/fmicb.2018.01953.

30. Vasireddy, L.; Bingle, L.E.H.; Davies, M.S. Antimicrobial activity of essential oils against multidrugresistant clinical isolates of the Burkholderia cepacia complex. PLoS One 2018, 13, https://doi.org/10.1371/journal.pone.0201835.

31. Helal, I.M.; El-Bessoumy, A.; Al-Bataineh, E.; Joseph, M.R.P.; Rajagopalan, P.; Chandramoorthy, H.C.; Ben Hadj Ahmed, S. Antimicrobial Efficiency of Essential Oils from Traditional Medicinal Plants of Asir Region, Saudi Arabia, over Drug Resistant Isolates. Biomed Res Int, 2019, 2019, https://doi.org/10.1155/2019/8928306.

32. Yap, P.S.; Yiap, B.C.; Ping, H.C.; Lim, S.H. Essential oils, a new horizon in combating bacterial antibiotic resistance. Open Microbiol J, 2014, 8, 6-14, https://doi.org/10.2174/1874285801408010006.

33. Ferreira, L.E.; Benincasa, B.I.; Fachin, A.L.; Franca, S.C.; Contini, S.; Chagas, A.C.S.; Beleboni, R.O. Thymus vulgaris L. essential oil and its main component thymol: Anthelmintic effects against Haemonchus contortus from sheep. Vet Parasitol, 2016, 228, 70-76, https://doi.org/10.1016/j.vetpar.2016.08.011.

34. LeBel, G.; Vaillancourt, K.; Bercier, P.; Grenier, D. Antibacterial activity against porcine respiratory bacterial pathogens and in vitro biocompatibility of essential oils. Arch Microbiol 2019, 201, 833-840, https://doi.org/10.1007/s00203-019-01655-7.

35. Santoro, G.F.; das Gracas Cardoso, M.; Guimaraes, L.G.; Salgado, A.P.; Menna-Barreto, R.F.; Soares, M.J. Effect of oregano (Origanum vulgare L.) and thyme (Thymus vulgaris L.) essential oils on Trypanosoma cruzi (Protozoa: Kinetoplastida) growth and ultrastructure. Parasitol Res 2007, 100, 783-790, https://doi.org/10.1007/s00436-006-0326-5.

36. Sokovic, M.; Glamoclija, J.; Ciric, A.; Kataranovski, D.; Marin, P.D.; Vukojevic, J.; Brkic, D. Antifungal activity of the essential oil of Thymus vulgaris L. and thymol on experimentally induced dermatomycoses. Drug Dev Ind Pharm, 2008, 34, 1388-1393, https://doi.org/10.1080/03639040802130053.

37. Faleiro, L.; Miguel, G.; Gomes, S.; Costa, L.; Venancio, F.; Teixeira, A.; Figueiredo, A.C.; Barroso, J.G.; Pedro, L.G. Antibacterial and antioxidant activities of essential oils isolated from Thymbra capitata L. (Cav.) and Origanum vulgare L. J Agric Food Chem 2005, 53, 8162-8168, https://doi.org/10.1021/jf0510079.

38. Oussalah, M.; Caillet, S.; Saucier, L.; Lacroix, M. Antimicrobial effects of selected plant essential oils on the growth of a Pseudomonas putida strain isolated from meat. Meat Sci 2006, 73, 236-244, https://doi.org/10.1016/j.meatsci.2005.11.019.

39. Tabti, L.; Dib Mel, A.; Gaouar, N.; Samira, B.; Tabti, B. Antioxidant and Antifungal Activity of Extracts of the Aerial Parts of Thymus capitatus (L.) Hoffmanns Against Four Phytopathogenic Fungi of Citrus sinensis. Jundishapur J Nat Pharm Prod 2014, 9, 49-54, https://doi.org/10.17795/jjnpp-13972.

40. Adams, R.P. Identification of Essential Oil Components By Gas Chromatography/Mass Spectrometry. 4th ed. Allured Publishing Corporation: Carol Stream, USA, 2007.

41. Magiorakos, A.P.; Srinivasan, A.; Carey, R.B.; Carmeli, Y.; Falagas, M.E.; Giske, C.G.; Harbarth, S.; Hindler, J.F.; Kahlmeter, G.; Olsson-Liljequist, B.; Paterson, D.L.; Rice, L.B.; Stelling, J.; Struelens, M.J.; Vatopoulos, A.; Weber, J.T.; Monnet, D.L. Multidrug-resistant, extensively drug-resistant and pandrugresistant bacteria: an international expert proposal for interim standard definitions for acquired resistance. Clin Microbiol Infect 2012, 18, 268-281, https://doi.org/10.1111/j.1469-0691.2011.03570.x.

42. C.L.S.I. M100 S29 Performance Standards for Antimicrobial Susceptibility Testing. Clinical Laboratory Standards Institute: 950 West Valley Road, Suite 2500, Wayne, Pennsylvania 19087 USA, 2019.

43. MicrochemLaboratory Minimum Bactericidal Concentration (MBC) Test. http://microchemlab.com/test/minimum-bactericidal-concentration-mbc-test (15 Jul),

44. Fuochi, V.; Barbagallo, I.; Distefano, A.; Puglisi, F.; Palmeri, R.; Di Rosa, M.; Giallongo, C.; Longhitano, L.; Fontana, P.; Sferrazzo, G.; Tiralongo, F.; Raccuia, S.A.; Ronsisvalle, S.; Li Volti, G.; Furneri, P.M.; Tibullo, D. Biological properties of Cakile maritima Scop. (Brassicaceae) extracts. Eur Rev Med Pharmacol Sci 2019, 23, 2280-2292, https://doi.org/10.26355/eurrev_201903_17277.

45. El-Azizi, M. Novel Microdilution Method to Assess Double and Triple Antibiotic Combination Therapy In Vitro. Int J Microbiol 2016, 5, 1-10, https://doi.org/10.1155/2016/4612021.

46. D’Arrigo, M.; Ginestra, G.; Mandalari, G.; Furneri, P.M.; Bisignano, G. Synergism and postantibiotic effect of tobramycin and Melaleuca alternifolia (tea tree) oil against Staphylococcus aureus and Escherichia coli. Phytomedicine 2010, 17, 317-322, https://doi.org/10.1016/j.phymed.2009.07.008.

47. Rosato, A.; Piarulli, M.; Corbo, F.; Muraglia, M.; Carone, A.; Vitali, M.E.; Vitali, C. In vitro synergistic antibacterial action of certain combinations of gentamicin and essential oils. Curr Med Chem 2010, 17, 32893295, https://doi.org/10.2174/092986710792231996.

48. Hsieh, M.H.; Yu, C.M.; Yu, V.L.; Chow, J.W. Synergy assessed by checkerboard. A critical analysis. Diagn Microbiol Infect Dis 1993, 16, 343-349, https://doi.org/10.1016/0732-8893(93)90087-N.

49. Stein, C.; Makarewicz, O.; Bohnert, J.A.; Pfeifer, Y.; Kesselmeier, M.; Hagel, S.; Pletz, M.W. Three Dimensional Checkerboard Synergy Analysis of Colistin, Meropenem, Tigecycline against MultidrugResistant Clinical Klebsiella pneumonia Isolates. PLoS One 2015, 10, https://doi.org/10.1371/journal.pone.0126479. 
50. MacKenzie, F.M.; Gould, I.M. The post-antibiotic effect. J Antimicrob Chemother 1993, 32, 519-537, https://doi.org/10.1093/jac/32.4.519.

51. Boswell, F.J.; Andrews, J.M.; Wise, R.; Dalhoff, A. Bactericidal properties of moxifloxacin and postantibiotic effect. J Antimicrob Chemother 1999, 43, 43-49, https://doi.org/10.1093/jac/43.suppl_2.43.

52. Gudmundsson, S.; Vogelman, B.; Craig, W.A. Decreased bactericidal activity during the period of the postantibiotic effect. J Antimicrob Chemother 1994, 34, 921-930, https://doi.org/10.1093/jac/34.6.921.

53. Fass, R.J.; Barnishan, J. Minimal inhibitory concentrations of 34 antimicrobial agents for control strains Escherichia coli ATCC 25922 and Pseudomonas aeruginosa ATCC 27853. Antimicrob Agents Chemother 1979, 16, 622-624, https://dx.doi.org/10.1128\%2Faac.16.5.622.

54. Bera, S.; Zhanel, G.G.; Schweizer, F. Antibacterial activity of guanidinylated neomycin B- and kanamycin A-derived amphiphilic lipid conjugates. $J$ Antimicrob Chemother 2010, 65, 1224-1227, https://doi.org/10.1093/jac/dkq083.

55. Nasiri, G.; Peymani, A.; Farivar, T.N.; Hosseini, P. Molecular epidemiology of aminoglycoside resistance in clinical isolates of Klebsiella pneumoniae collected from Qazvin and Tehran provinces, Iran. Infect Genet Evol 2018, 64, 219-224, https://doi.org/10.1016/j.meegid.2018.06.030.

56. Ultee, A.; Slump, R.A.; Steging, G.; Smid, E.J. Antimicrobial activity of carvacrol toward Bacillus cereus on rice. J Food Prot 2000, 63, 620-624, https://doi.org/10.4315/0362-028x-63.5.620.

57. Qin, C.; Tan, K.L.; Zhang, C.L.; Tan, C.Y.; Chen, Y.Z.; Jiang, Y.Y. What Does It Take to Synergistically Combine Sub-Potent Natural Products into Drug-Level Potent Combinations? Plos One 2012, 7, https://doi.org/10.1371/journal.pone.0049969.

58. Wagner, H.; Ulrich-Merzenich, G. Synergy research: approaching a new generation of phytopharmaceuticals. Phytomedicine 2009, 16, 97-110, https://doi.org/10.1016/j.phymed.2008.12.018.

59. Yavari, A.; Nazeri, V.; Sefidkon, F.; Hassani, M.E. Influence of some environmental factors on the essential oil variability of Thymus migricus. Nat Prod Commun 2010, 5, 943-948.

60. Barra, A. Factors affecting chemical variability of essential oils: a review of recent developments. Nat Prod Commun 2009, 4, 1147-1154.

61. Boira, H.; Blazquez, M.A. Environmental factors affecting chemical variability of essential oils in Thymus piperella L. Biochemical Systematics and Ecology 1998, 26, 811-822, https://doi.org/10.1016/S03051978(98)00047-7.

62. Rosato, A.; Carocci, A.; Catalano, A.; Clodoveo, M.L.; Franchini, C.; Corbo, F.; Carbonara, G.G.; Carrieri, A.; Fracchiolla, G. Elucidation of the synergistic action of Mentha Piperita essential oil with common antimicrobials. PLoS One 2018, 13, https://doi.org/10.1371/journal.pone.0200902.

63. Ben Arfa, A.; Combes, S.; Preziosi-Belloy, L.; Gontard, N.; Chalier, P. Antimicrobial activity of carvacrol related to its chemical structure. Lett Appl Microbiol 2006, 43, 149-154, https://doi.org/10.1111/j.1472765X.2006.01938.x.

64. Owen, L.; Laird, K. Synchronous application of antibiotics and essential oils: dual mechanisms of action as a potential solution to antibiotic resistance. Crit Rev Microbiol 2018, 44, 414-435, https://doi.org/10.1080/1040841X.2018.1423616.

65. Khoury, M.; El Beyrouthy, M.; Ouaini, N.; Eparvier, V.; Stien, D. Hirtellina lobelii DC. essential oil, its constituents, its combination with antimicrobial drugs and its mode of action. Fitoterapia 2019, 133, 130136, https://doi.org/10.1016/j.fitote.2019.01.001.

66. Utchariyakiat, I.; Surassmo, S.; Jaturanpinyo, M.; Khuntayaporn, P.; Chomnawang, M.T. Efficacy of cinnamon bark oil and cinnamaldehyde on anti-multidrug resistant Pseudomonas aeruginosa and the synergistic effects in combination with other antimicrobial agents. BMC Complement Altern Med 2016, 16, https://doi.org/10.1186/s12906-016-1134-9.

67. Valcourt, C.; Saulnier, P.; Umerska, A.; Zanelli, M.P.; Montagu, A.; Rossines, E.; Joly-Guillou, M.L. Synergistic interactions between doxycycline and terpenic components of essential oils encapsulated within lipid nanocapsules against gram negative bacteria. Int $J$ Pharm 2016, 498, 23-31, https://doi.org/10.1016/j.ijpharm.2015.11.042.

68. Knezevic, P.; Aleksic, V.; Simin, N.; Svircev, E.; Petrovic, A.; Mimica-Dukic, N. Antimicrobial activity of Eucalyptus camaldulensis essential oils and their interactions with conventional antimicrobial agents against multidrug resistant Acinetobacter baumannii. $J$ Ethnopharmacol 2016, 178, 125-136, https://doi.org/10.1016/j.jep.2015.12.008.

69. El Atki, Y.; Aouam, I.; El Kamari, F.; Taroq, A.; Nayme, K.; Timinouni, M.; Lyoussi, B.; Abdellaoui, A. Antibacterial activity of cinnamon essential oils and their synergistic potential with antibiotics. J Adv Pharm Technol Res 2019, 10, 63-67, https://doi.org/10.4103/japtr.JAPTR_366_18.

70. Nikkhah, M.; Hashemi, M.; Habibi Najafi, M.B.; Farhoosh, R. Synergistic effects of some essential oils against fungal spoilage on pear fruit. Int J Food Microbiol 2017, 257, 285-294, https://doi.org/10.1016/j.ijfoodmicro.2017.06.021.

71. Wolinsky, E.; Hines, J.D. Neurotoxic and nephrotoxic effects of colistin in patients with renal disease. $N$ Engl J Med 1962, 266, 759-762, https://doi.org/10.1056/NEJM196204122661505. 
72. Wrzesniok, D.; Rok, J.; Beberok, A.; Rzepka, Z.; Respondek, M.; Pilawa, B.; Zdybel, M.; Delijewski, M.; Buszman, E. Kanamycin induces free radicals formation in melanocytes: An important factor for aminoglycosides ototoxicity. J Cell Biochem 2018, 119, 1-9, https://doi.org/10.1002/jcb.26817.

73. Tamma, P.D.; Cosgrove, S.E.; Maragakis, L.L. Combination therapy for treatment of infections with gramnegative bacteria. Clin Microbiol Rev 2012, 25, 450-470, https://doi.org/10.1128/CMR.05041-11.

74. Puglia, C.; Pignatello, R.; Fuochi, V.; Furneri, P.M.; Lauro, M.R.; Santonocito, D.; Cortesi, R.; Esposito, E. Lipid Nanoparticles And Active Natural Compounds: A Perfect Combination For Pharmaceutical Applications. Curr Med Chem 2019, 26, 4681-4696, https://doi.org/10.2174/0929867326666190614123835.

75. Pignatello, R.; Leonardi, A.; Fuochi, V.; Petronio Petronio, G.; Greco, A.S.; Furneri, P.M. A Method for Efficient Loading of Ciprofloxacin Hydrochloride in Cationic Solid Lipid Nanoparticles: Formulation and Microbiological Evaluation. Nanomaterials (Basel) 2018, 8, https://doi.org/10.3390/nano8050304.

76. Furneri, P.M.; Fuochi, V.; Pignatello, R. Lipid-based Nanosized Delivery Systems for Fluoroquinolones: a Review. Curr Pharm Des 2017, 23, 1-9, https://doi.org/10.2174/1381612823666171122110103.

77. Carbone, C.; Teixeira, M.D.C.; Sousa, M.D.C.; Martins-Gomes, C.; Silva, A.M.; Souto, E.M.B.; Musumeci, T. Clotrimazole-Loaded Mediterranean Essential Oils NLC: A Synergic Treatment of Candida Skin Infections. Pharmaceutics 2019, 11, https://doi.org/10.3390/pharmaceutics11050231. 


\section{Supplementary files}

\section{Materials and Methods}

\section{$M I C$ and $M B C$ assays}

Bacteria used to belong to the collection of the Laboratory of Applied Microbiology (Department of Biomedical and Biotechnological Sciences, Università degli Studi di Catania, Italy). The strains were designated as multidrug resistant (MDR) by International standard definitions for acquired resistance. MDR was defined as acquired non-susceptibility to at least one agent in three or more antimicrobial categories following the rules described by Magiorakos et al [41]. The antibiotics used to assess their level of resistance/sensitivity, according to guidelines of CLSI [42], were summarized in Table S1.

Table S1. Antimicrobial categories and agents used to define MDR following rules described by Magiorakos et al (2012): non-susceptible to $\geq 1$ agent in $\geq 3$ antimicrobial categories.

\begin{tabular}{|c|c|c|}
\hline & Categories & Resistant to .. \\
\hline \multirow{4}{*}{ Acinetobacter baumannii } & Aminoglycosides & Gentamicin; Amikacin \\
\hline & Antipseudomonal cephalosporins & Ceftazidime; Cefepime \\
\hline & Antipseudomonal fluoroquinolones & Ciprofloxacin \\
\hline & Polymyxins & Colistin \\
\hline \multirow{3}{*}{ Enterococcus faecalis } & Aminoglycosides & Gentamicin \\
\hline & Streptomycin & Streptomycin (high level) \\
\hline & Penicillins & Ampicillin \\
\hline \multirow{6}{*}{ Escherichia coli } & Fluoroquinolones & Ciprofloxacin \\
\hline & Folate pathway inhibitors & Trimethoprim-sulphamethoxazole \\
\hline & Monobactams & Aztreonam \\
\hline & Penicillins & Ampicillin \\
\hline & Phenicols & Chloramphenicol \\
\hline & Polymyxins & Colistin \\
\hline \multirow{4}{*}{ Klebsiella pneumoniae } & Monobactams & Aztreonam \\
\hline & Penicillins & Ampicillin \\
\hline & Phenicols & Chloramphenicol \\
\hline & Polymyxins & Colistin \\
\hline \multirow{4}{*}{ Pseudomonas aeruginosa } & Aminoglycosides & Gentamicin \\
\hline & Antipseudomonal fluoroquinolones & Ciprofloxacin; Levofloxacin \\
\hline & Phosphonic acids & Fosfomycin \\
\hline & Polymyxins & Colistin \\
\hline \multirow{5}{*}{ Staphylococcus aureus* } & Aminoglycosides & Gentamicin \\
\hline & Anti-staphylococcal $\beta$-lactams & Oxacillin \\
\hline & Fluoroquinolones & Ciprofloxacin \\
\hline & Lincosamides & Clindamycin \\
\hline & Macrolides & Erythromycin \\
\hline
\end{tabular}

*an MRSA is always considered MDR by virtue of being an MRSA.

\section{Results}

GC-MS analysis

Table S2. GC characterization of Thymus capitatus var. coridothymus essential oil.

\begin{tabular}{c|c|c}
\multicolumn{2}{|c}{ Res. Type TIC. } \\
RT (min) & Peak name & Area \\
\hline 6.522 & $\beta$-Thujene & $1.01 \mathrm{E}+09$ \\
\hline 6.77 & $\alpha$-Pinene & $7.46 \mathrm{E}+08$ \\
\hline 7.34 & Camphene & $1.62 \mathrm{E}+08$ \\
\hline 8.328 & $\beta$-Pinene & $9.67 \mathrm{E}+07$ \\
\hline 8.733 & $\beta$-Myrcene & $8.54 \mathrm{E}+08$ \\
\hline 9.434 & $\alpha$-Phellandrene & $2.05 \mathrm{E}+08$ \\
\hline 9.83 & Terpinolene & $1.06 \mathrm{E}+09$ \\
\hline 10.163 & p-Cymene & $5.91 \mathrm{E}+09$ \\
\hline 10.328 & p-Mentha-1,3,8-triene & $1.68 \mathrm{E}+07$
\end{tabular}




\begin{tabular}{c|c|c} 
RT $(\mathbf{m i n})$ & Peak name & Area \\
\hline 11.549 & $\gamma$-Terpinene & $2.70 \mathrm{E}+09$ \\
\hline 13.465 & $\beta$-Linalool & $2.94 \mathrm{E}+08$ \\
\hline 16.645 & Borneol & $2.65 \mathrm{E}+08$ \\
\hline 17.09 & L-Terpinen-4-ol & $2.12 \mathrm{E}+08$ \\
\hline 22.175 & Thymol & $1.36 \mathrm{E}+08$ \\
\hline 22.551 & Carvacrol & $4.56 \mathrm{E}+10$ \\
\hline 27.319 & $\beta$-Caryophillene & $3.15 \mathrm{E}+09$
\end{tabular}

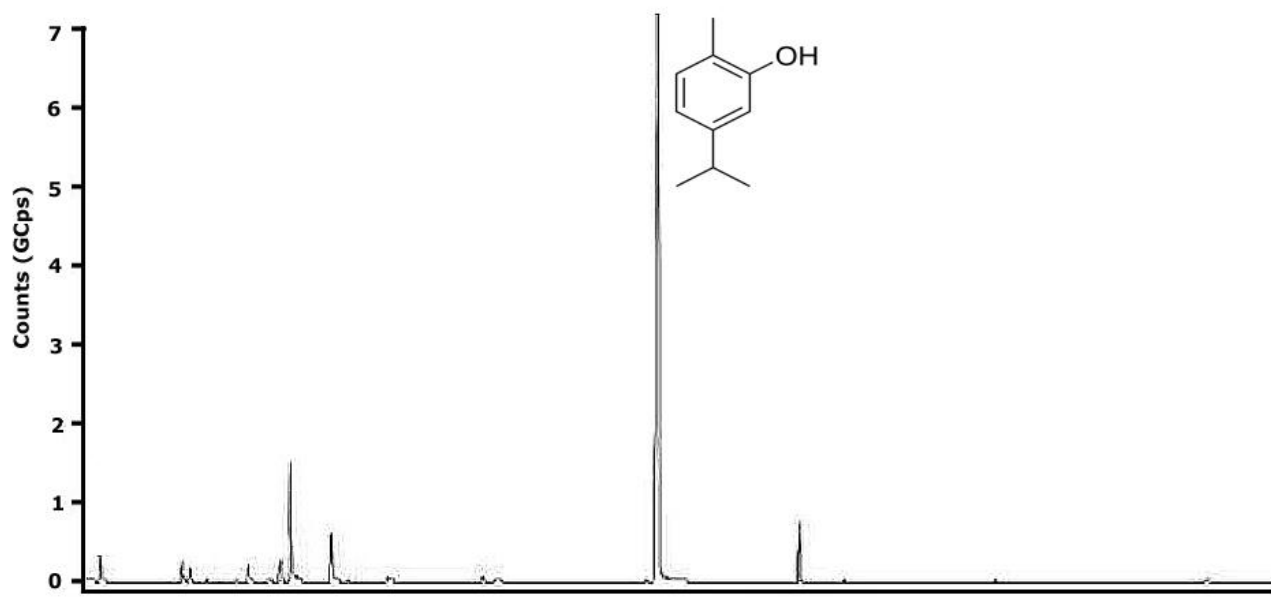

Figure S1. Chromatogram of Thymus capitatus var. coridothymus essential oil. 